\title{
Analysis of Best Practice Policy and Benchmarking Behavior for Government Knowledge Management
}

\author{
Kyoung Jun Lee ${ }^{1}$ and Byul Jeon ${ }^{2}$ \\ ${ }^{1}$ School of Business, Kyung Hee University \\ Hoegi-Dong, Dongdaemun-Ku, Seoul, Korea \\ klee@khu.ac.kr \\ ${ }^{2}$ Knowledge Center for Public Administration and Policy \\ San 56-1, Shillim-dong, Kwanak-ku, Seoul 151-742, Korea \\ Star7@know.or.kr
}

\begin{abstract}
Korean government has several best practice competition and diffusion programs for the purpose of public administration reform and the improvement of government service. From the perspective of knowledge management, this paper evaluates the best practice policy and analyzes the main factors influencing the recognition, adoption and utilization of best practices through the email-based survey and interview with local government officers. The result shows that 1) The government officers' recognition of best practice programs and the best practices themselves is not high, 2) The adoption and utilization of a best practice is affected by its value and officer's information needs, 3) Raising the recognition of Best practice policy affects the recognition and adoption of a best practice, and 4) The recognition and utilization of a best practice is affected by the work experience. The result gives important implications for designing and implementing government knowledge management systems and strategies.
\end{abstract}

\section{Introduction}

Korea's Ministry of Planning \& Budget (MPB), Propulsive Committee of Government Innovation (PCGI), and Ministry of Government Administration \& Home Affairs (MOGAHA) have held the Public Innovation Conference, the Best Practice Conference for Public Reform, and the Local Government Reform Exhibition respectively with the aim of diffusing best practices to local governments. We may call these kinds of efforts 'best practice policy', which leads local governments to benchmark best practices from central governments and each other. We view a best practice policy as a nation-wide knowledge management initiative. With the emergence and the rapid development of digital networks like Internet, now the best practice policy needs to be formulated, implemented, and evaluated based on the knowledge management and electronic government framework. Especially, a best practice policy should be supported by government knowledge management systems.

From the perspective of knowledge management, this paper evaluates the best practice policy and analyzes the main factors influencing the recognition, adoption and utilization of best practices through the email-based survey and interview with 
local government officers. The result is expected to give important implications for designing and implementing government knowledge management systems and strategies.

In Section 2, we introduce best practice policies of Korean government. In Section 3 , we evaluate them from program verification level and discuss the implications of the evaluation. In Section 4, we analyze the best practice benchmarking behavior of government officers and draw some implications for designing and implementing government knowledge management systems and their strategies. Section 5 concludes this paper by proposing the concept of system policy, which emphasizes the interplay between systems and policies.

\section{Current Status of Best Practice Policy Programs}

The instruments of best practice policy in Korea have been the conference, exhibition, paper publications, and Web pages. However, it has not been known and evaluated how much best practices have been practically diffused to and shared among local governments. We have known neither whether local civil servants have recognized best practices nor how they have adopted and utilized the best practices for their own policymaking. In order to diffuse best practices to local governments efficiently and effectively, it is necessary to evaluate the current best practice policy and investigate the problems in the policy implementation.

The Public Innovation Conference is held annually by Ministry of Planning \& Budget and Ministry of Government Administration \& Home Affairs to select and award prizes to public organizations, including central agencies, local agencies, and public enterprises which successfully innovated their management and services. The winning organizations chosen by review committee have benefits such as press release, invitation to the Presidential Office, and the bounty etc. The conference was introduced in 1999 to give incentives to the public innovation efforts which had not made much progress compared with those of private sectors.

The Best Practice Conferences for Public Reform were held five times at different regions in 2001, by Propulsive Committee of Government Innovation, to present and promote best reform cases that local governments can benchmark. The cases are recommended by central and local agencies. The conference was introduced for especially local governments, that is, for supporting and promoting their reforms.

The Local Government Reform Exhibition was co-held by the Ministry of Government Administration \& Home Affairs (MOGAHA) and the Citizen's Coalition for Economic Justice (CCEJ), a famous NGO in Korea, in 2000 and 2002. The local government reform cases were gathered and reviewed by MOGAHA and CCEJ, and the best practices selected were announced to be used as benchmarking cases. The 2000 exhibition presented 78 best practices and the 2002 exhibition 82 ones.

We found that the best practice policy programs had not been systematically evaluated. An evaluation result [7] shows that the current evaluation of best practice policy is oriented only to PR (public relations) activities themselves rather than its effect on the adoption and utilization of best practices. Especially, the Ministry of Planning and Budget has no procedure or system for evaluating programs such as the Public Innovation Conference and the Best Practice Conference for Public Reform.

To be summarized, the current status of evaluation has problems as follows: 
1. The current evaluation does not evaluate the status of best practice diffusion and reuse.

2. The current PR activity-oriented evaluation does not evaluate the effect of the programs on the diffusion and reuse of best practices in local governments.

3. The current evaluation has no systematic evaluation mechanism and cannot identify the effectiveness, efficiency, problems and difficulties of the program implementation.

To overcome the current evaluation system, in this paper, we evaluate the performance of best practice policy by investigating the recognition of the programs themselves and the diffusion and reuse of best practices.

\section{Evaluation of Best Practice Policy and Its Implications}

For the evaluation of best practice policy, we used e-mail-based survey and deep interview method investigating the recognition and the reuse of best practices by local government officers. The survey emails were sent to the 115 local governments including provincial governments, metropolitan city governments, local city governments and city district offices. We interviewed six local government officers among the email survey respondents for identifying the factors limiting the diffusion and reuse of best practices.

The target recipients were limited to the officers performing the role of general administration and planning or best practice related tasks. The email addresses were gathered from the homepages of the local governments and 700 survey mails were delivered. The 110 responses were gathered and the response rate was $16 \%$. The respondents are evenly distributed in terms of the size of region, the age of respondents, and the location of the region.

We evaluate the best practice policy by the program verification level among the Fischer [3]'s four levels of policy evaluation: program verification evaluating program outcomes, situation validation evaluating program objectives, societal-level vindication evaluating policy goals, and social choice evaluating ideological commitments. The program verification tries to answer the questions such as 1) Does the program empirically fulfill its stated objectives? 2) Does the empirical analysis uncover secondary or unanticipated effects that offset program objectives? and 3) Does the program fulfill the objectives more efficiently than alternative means available? Accordingly, we review 1) whether best practices have been diffused through best practice policy programs, 2) what factors have limited the diffusion and the reuse of best practices, and 3) whether the instruments of best practice policy have been efficient.

\subsection{Verification on Best Practice Diffusion}

On the average, about $70 \%$ of the respondents recognized the programs. Since the respondents play a role related to the best practice, we cannot say the program recognition level is satisfactory. 
To investigate the level of recognition of best practices, we chose a best practice 'The big-deal of basic environmental facilities in Gwangmyeong City' as a sample. The best practice is famous and has been selected by all the three best practice policy programs. This is the case where the Guro District of Seoul, a district of the Capital of Korea, and the Gwangmyeong City, a satellite city of Seoul, reached an agreement to share their environment facilities. Through the 'big-deal', the municipal solid wastes produced in Guro District are processed by the trash burning facility in Gwangmyeong City and the organic wastes produced in Gwangmyeong City are treated by the sewage treatment plant of Guro District. This case, the first instance of agreement on the sharing of environmental facilities between local governments, was introduced first at the 2000 Local Government Reform Exhibition, presented at the 2001 Best Practice Conference for Public Reform, and received the Minister Award at the 2001 Public Innovation Conference. Since the case was introduced at all the three best practice policy programs, it is appropriate to be used for verifying the effectiveness of best practice policy.

The survey result shows that only $40 \%$ of the respondents knew the 'The big-deal of basic environmental facilities in Gwangmyeong City' case. The low level of recognition of the most 'famous' best practice shows that the diffusion of best practices has not been effective.

\subsection{Factors Limiting the Diffusion and Reuse}

To identify what limited the diffusion of best practices, we interviewed six local government officers. Most of local government officers have not been interested in the best practice related conferences and have even avoided attending them. The first reason of this indifference is the lack of motivation, the one of the top four important issues in knowledge management [4]. Even though a local government participates in such a conference and gets an award from it, there is not much benefit as a special budget support. Therefore, attending the conference is just a cost or burden to government officers. The second reason is the lack of resources. Small local governments, especially if they are not financially rich, are difficult to apply for the conferences without financial support from the conference organization. The third reason is the lack of opportunity. Local government officers perceive that best practices have been selected based on the criteria affected by absolute size of the case. Since many small local governments are not easy to outperform bigger local governments or central government agencies, their officers have become indifferent to best practice policy. The interviewee agreed that the 'Gwangmyeong City' case is excellent and very much applicable to the practice of other local governments. However, the diffusion of best practices does not work only with providing knowledge on the case.

\subsection{Efficiency of the Policy Instruments}

The major instrument of MPB and MOGAHA for diffusing best practices is holding the conferences. In addition, they used official document delivery, case paper book publication, and homepage etc. However, from the public officer's point of view, the instruments used for receiving the 'Gwangmyeong City' case are summarized in Table 1. Local government officers get knowledge on best practices mostly from 
press, official document, and conference proceedings etc. The conferences themselves have not affected much impact on the recognition of best practices.

Table 1. Instrument Use for Best Practice Reception

\begin{tabular}{|l|l|l|l|l|l|}
\hline Peers & Press & Conference & $\begin{array}{l}\text { Paper } \\
\text { Newsletter }\end{array}$ & $\begin{array}{l}\text { Online } \\
\text { Newsletter }\end{array}$ & Homepage \\
\hline $8.7 \%$ & $16.8 \%$ & $6.7 \%$ & $6.0 \%$ & $3.4 \%$ & $8.7 \%$ \\
\hline $\begin{array}{l}\text { Official } \\
\text { Document }\end{array}$ & $\begin{array}{l}\text { City PR } \\
\text { paper }\end{array}$ & $\begin{array}{l}\text { Province } \\
\text { PR Paper }\end{array}$ & $\begin{array}{l}\text { Ministry PR } \\
\text { Paper }\end{array}$ & $\begin{array}{l}\text { Conference } \\
\text { Proceedings }\end{array}$ & $\begin{array}{l}\text { Miscellane- } \\
\text { ous }\end{array}$ \\
\hline $12.1 \%$ & $8.7 \%$ & $5.4 \%$ & $4.0 \%$ & $10.7 \%$ & $8.7 \%$ \\
\hline
\end{tabular}

On the other hand, officers introduce best practices to other officers or organizations by the following ways summarized in Table 2 . The most frequently used channels for recommending best practices are referring to peers $(25 \%)$, referring to team leaders $(12.5 \%)$, and referring to inter-department meeting $(12.5 \%)$. The fact means the diffusion of best practices is carried personally and horizontally rather than organizationally or vertically.

Table 2. Instrument Use Rate for Best Practice Recommendation

\begin{tabular}{|l|l|l|l|l|}
\hline To Peers & $\begin{array}{l}\text { To Team Lead- } \\
\text { ers }\end{array}$ & $\begin{array}{l}\text { To Head of } \\
\text { Department }\end{array}$ & To Governors & Team Meeting \\
\hline $25.0 \%$ & $12.5 \%$ & $5.8 \%$ & $4.8 \%$ & $9.6 \%$ \\
\hline $\begin{array}{l}\text { Department } \\
\text { Meeting }\end{array}$ & $\begin{array}{l}\text { Inter-department } \\
\text { Meeting }\end{array}$ & $\begin{array}{l}\text { Governor } \\
\text { Meeting }\end{array}$ & $\begin{array}{l}\text { Inter-Governor } \\
\text { Meeting }\end{array}$ & Miscellaneous \\
\hline $5.8 \%$ & $12.5 \%$ & $3.8 \%$ & $3.8 \%$ & $16.3 \%$ \\
\hline
\end{tabular}

Current best practice policy adopts a top-down approach where best practices are diffused from central government agencies to local governments. In addition, the policy is implemented mostly by the events such as the Public Innovation Conference, the Best Practice Conference for Public Reform, and the Local Government Reform Exhibition etc. However, our survey result shows that the actual diffusion of best practices is done horizontally rather than vertically.

\subsection{Policy Implications of Best Practice Policy Evaluation}

From the results of the policy evaluation, we have inferred the following policy implications:

1. Current offline 'event'-based best practice policy programs have not been effective even in promoting themselves and diffusing best practices to government offices. It raises the necessity of a new best practice policy based on government knowledge management system that emphasizes the continuing 'relationship' with government officers rather than one-time 'event' such as conferences. The old offline-based best practice policy should be reformed into a new best practice policy based on a sort of lessons learned systems [11] and case-based decision support system [2, 6].

2. Best practice policies should give government officers incentives and resources to apply best practices into their work. Especially in public sectors, "this is my idea" 
syndrome is very common. Public officers do not have much incentive to adopt other's practices to their own domain. Therefore the incentives and resources should be given to the adoption and reuse of best practices as well as their creation.

3. While current best practice polices have diffused best practices vertically between organizations, actually the government officers share their cases personally, i.e. horizontally. It means that best practice policy should support the personal and horizontal sharing of best practices between public officers. To perform and support the personal and horizontal sharing of best practices, a non-governmental organization might be more appropriate than official government organization. The existence of this kind of an intermediary is one of governance mechanism [8] for government knowledge management.

\section{Benchmarking Behavior Analysis and Its Implications}

Diffused best practices produce real values when they are benchmarked by public officers. The steps for benchmarking best practices are classified as recognition, adoption, and utilization. Recognition is to know the existence of a best practice, adoption is to have the intention to apply a best practice to a new problem, and utilization is the real action of applying a best practice to a new problem. In this section, using the survey data, we investigate the factors affecting the government officer's benchmarking behaviors such as recognition, adoption, and utilization of best practices.

Table 3. Dependent and Independent Variables

\begin{tabular}{|c|c|c|c|c|}
\hline \multirow{2}{*}{\multicolumn{2}{|c|}{ Classifications }} & \multicolumn{3}{|c|}{ Benchmarking Steps } \\
\hline & & Recognition & Adoption & Utilization \\
\hline \multirow{8}{*}{$\begin{array}{c}\text { Inde- } \\
\text { pendent } \\
\text { Variables }\end{array}$} & \multirow{3}{*}{$\begin{array}{c}\text { Organizational } \\
\text { Attributes }\end{array}$} & \multicolumn{3}{|c|}{ Size of Local Governments } \\
\hline & & \multicolumn{3}{|c|}{ Status in Organization } \\
\hline & & \multicolumn{3}{|c|}{ Best Practice Related Work Experience } \\
\hline & \multirow{2}{*}{$\begin{array}{c}\text { Policy } \\
\text { Recognition }\end{array}$} & \multicolumn{3}{|c|}{ Recognition of Best Practice Policy Efforts } \\
\hline & & \multicolumn{3}{|c|}{ Recognition of the Best Practice Conferences } \\
\hline & $\begin{array}{c}\text { Case Charac- } \\
\text { teristics }\end{array}$ & \multicolumn{3}{|c|}{ Perceived Value of Best Practice } \\
\hline & \multirow{2}{*}{$\begin{array}{l}\text { Attitudes on } \\
\text { Knowledge }\end{array}$} & \multicolumn{3}{|c|}{ Demand on Policy Information } \\
\hline & & \multicolumn{3}{|c|}{ Efforts on Policy Information Search } \\
\hline \multicolumn{2}{|c|}{ Dependent Variables } & $\begin{array}{c}\text { Best Prac- } \\
\text { tice Recog- } \\
\text { nition }\end{array}$ & $\begin{array}{c}\text { Best } \\
\text { Practice } \\
\text { Adoption }\end{array}$ & $\begin{array}{c}\text { Best Practice } \\
\text { Utilization }\end{array}$ \\
\hline
\end{tabular}

We hypothesize that the four categories of factors affect the benchmarking behavior of public officers: public officer's organizational attributes, public officer's recognition on best practice policy, best practice characteristics, and public officer's atti- 
tude on knowledge. The organizational attributes include the size of the local government which a government officer works for, her or his status in the organization, and the level of experience on best practice related job. The policy recognition variables include the level of recognition of the central government's best practice policy efforts and the recognition of the three best practice conferences. The best practice characteristic variable is measured as the perceived value of best practice. The attitude variables include the level of demand on policy information and the level of efforts of the government officers on information search. The dependent variables are the level of government officers' recognition, adoption, and utilization of best practices. The independent and dependent variables are summarized in Table 3.

We employ the logistic linear regression for the analysis and the result is summarized as follows:

1. The recognition of best practice is influenced by the best practice related work experience $(\mathrm{p}$-value $=0.005)$ and the recognition of best practice conference $(\mathrm{p}$ value $=0.018)$.

2. The adoption of best practice is influenced by the perceived value of best practice ( $\mathrm{p}$-value $=0.012)$, the demand on policy information $(\mathrm{p}$-value $=0.019)$, and the recognition on best practice policy efforts ( $p$-value $=0.036$ ).

3 . The utilization of best practice is influenced by the best practice related work experience $(p-$ value $=0.015)$, the perceived value of best practice $(p$-value $=0.026)$, and the demand on policy information ( $p$-value $=0.031$ ).

4. The variables such as the size of organization, the status of government officers, the efforts on the policy information search are not significant in our analysis.



Fig. 1. Influence Relationship in Benchmarking Behavior

The above results are integrated and reinterpreted as follows and described as Figure 1.

1. Though the recognition of best practice is not affected by its perceived value, but its adoption and utilization is affected by its value. 
2. Though raising the recognition of best practice policy affects the recognition and adoption of a best practice, but does not affect its reuse to a new domain.

3. Though the adoption of best practice is not affected by the work experience of officers, but its utilization is affected by the work experience.

The officers, whose demand on policy information is high, are eager to adopt and reuse best practices.

\subsection{Implications of Benchmarking Behavior Analysis}

The processes of Case-Based Reasoning (CBR), which gives more emphasis on the computer-based automatic case adaptation [5] than human direct use (i.e. benchmarking) of cases, consist of case retrieval, case reuse, case revision, and case retain [1]. The case retrieval of CBR corresponds to the recognition step of benchmarking, the case reuse to the adoption step, and the case revision to the utilization step. The similarity between the KM processes and CBR steps has been already discussed in [9, 10]. The similarity between the processes implies that the result of analyzing the best practice benchmarking behavior can be applied to the design of knowledge management system. The interpretation on benchmarking behavior analysis gives interesting implications to the government knowledge management systems as follows:

1. For the wide adoption and reuse of best practices, we should raise their potential value perceived to government officers. It means that the government knowledge management systems should accept only high-quality best practices and diffuse them to the target customers who will value them high.

2. The efforts for raising the recognition of best practice policy will raise the recognition and adoption of best practice rather than its reuse. It means that the efforts for the reuse and those for the other processes should be separate and evaluated respectively. It does not mean to devaluate the efforts for raising the recognition of best practice policy. Since the utilization cannot be done without adoption and recognition, the PR (Public Relations) efforts are still important.

3. Best practices should be delivered to officers whose information demand is high for their wide adoption and reuse. The knowledge management systems should have some measurement mechanism to identify the public officers with high information needs.

4. To raise the utilization of best practices, we need to deliver them to the workers experienced on best practice related task. It means that the knowledge management systems should have personalized case distribution systems to recognize the officers who have experience related to the delivered best practice.

\section{Discussions and Conclusions}

KP\&P (Knowledge Center for Public Administration \& Policy, http://www.know.or.kr/) is a government-supported organization located at a national university of Korea. With the aim to support effective public decision making and promote informatization of the public sector, the center has tried to systematically collect, analyze, manage, and disseminate the information and knowledge produced in the various communities 
of public sector. The center has emphasized its role as the internet library that contains public administration and policy database and tries to provide tailored knowledge when in demand.

The authors of this paper have worked for this center and the analysis introduced in this paper has been carried out for extracting strategic implications for the design and operation of the government knowledge management system. As we saw in previous sections, current offline-based best practice policy in Korea has been ineffective. The current best practice policies have been limited to 'events' rather than having consistent relationship with public officers. There has been no central intermediary organization or systems for accumulating, evaluating, and diffusing best practices. The lack of an official intermediary results in the problems of lack of responsibility and integration. The center, KP\&P, has aimed to play a role of an intermediary or a catalyst for best practice sharing though it is not official and just a university-based organization.

At first, the center used a 'pull' strategy rather than 'push' strategy. It gathered best practices and therefore accumulated about five hundred cases on its Web sites. Government officers could freely visit the site and download the cases. However, the usage rate was not high. The center determined its strategy from 'pull' strategy to 'push' strategy. The background of the strategy change is closely related to the characteristics of best practices. Best practices are a sort of perishable goods whose value deteriorates drastically as time goes. The center determined to diffuse best practices to government officers through email. Before designing and implementing the best practice diffusion system, we needed to evaluate current best practice policies and analyze benchmarking behavior of government officers. From the result, we could extract valuable implications for the new government knowledge management system such as those described in this paper.

Modern policy cannot succeed without a proper information system support and a public information system cannot succeed without a discreet policy consideration. Designing a knowledge management system for public sectors should also start with a systematic evaluation of existing knowledge management policy, for example, best practice policy. E-government is the typical and representative area where systems and policy consideration should be integrated. We may call these efforts 'system policy'. In this paper, we showed an example of system policy research. Based on the system policy perspective, in this paper, we illustrated that the evaluation result of existing best practice policy can be utilized for the design of a new knowledge management system for public sectors and the new best practice policy can be formulated and implemented considering the effective use of government knowledge management systems.

\section{References}

1. Aamodt, A., and Plaza, E. Case-based reasoning: foundational issues, methodological variations, and system approaches, AI Communication 7 (1) 39- 59. (1994)

2. Dutta, S., Wierenga, B., and Dalebout, A., Case-Based Reasoning Systems: From Automation to Decision-Aiding and Stimulation, IEEE Trans. on Knowledge and Data Engineering 9(6): 911-922 (1997)

3. Fischer, F., Evaluating Public Policy, Nelson-Hall Publishers, Chicago (1995) 
4. King, W., Marks, P., and McCoy, S., The Most Important Issues in Knowledge Management, Communications of the ACM, 45(9):93-97(2002)

5. Lee, K., Kim, H., Lee, J., and Kim, T., Case- and Constraint-Based Project Planning for Apartment Construction, AI Magazine 19(1): 13-24, Spring (1998)

6. Liao, S., Case-based decision support system: Architecture for simulating military command and control, European Journal of Operational Research 123: 558-567 (2000)

7. OGPC, The 2002 Report for Government Activity Evaluation Result, Office for Government Policy Coordination (2002)

8. Pierre, J. and Peters, B., Governance, Politics, and the State, NY: St. Martin's Press, 2000

9. Watson, I., A Decision Support System for Local Government Regulatory Advice, FLAIRS Conference 329-333 (2001)

10. Watson, I., Knowledge Management and Case-Based Reasoning: A Perfect Match?, FLAIRS Conference 118-122 (2001)

11. Weber, R. and Aha, D., Intelligent delivery of military lessons learned, Decision Support Systems 34: 287-304 (2002) 